\title{
The Relationship between Perceived School Climate and the Adolescents' Adherence to Humanitarian Values
}

\author{
Muhammed Turhan ${ }^{1, *}$, Tülin Akgül ${ }^{2}$ \\ ${ }^{1}$ Faculty of Education, Firat University, Turkey \\ ${ }^{2}$ Mehmet Akif Ersoy Primary School, Turkey
}

Copyright $\bigcirc 2017$ by authors, all rights reserved. Authors agree that this article remains permanently open access under the terms of the Creative Commons Attribution License 4.0 International License

\begin{abstract}
This study investigates the relationship between students' perception of school climate and their adherence to humanitarian values. To this end, the study group consisted of 1094 students in 21 secondary schools in Elazığ province of Turkey. The "School Climate Scale," developed by Çalık and Kurt [1], and the "Humanitarian Values Scale," developed by Dilmaç [2], were used to collect data. The findings of the study indicated that female students have a higher level of adherence to humanitarian values. In addition, it was found that school activities towards values education have a significant effect on adherence to humanitarian values. It was concluded that teacher support, success orientation and safe learning environment-positive peer interactions, which are important components of positive school climate, positively affect adolescents' adherence to humanitarian values. In parallel with these findings, some recommendations were made, which can be applied to the building school environment for practitioners.
\end{abstract}

Keywords School Climate, Humanitarian Values, Adolescent

\section{Introduction}

Social learning theory suggests that people's attitudes and behaviors are not solely related to objective reality but also to their perception [3]. From this perspective, the school environment affects students' experiences and behaviors through their perceptions. For this reason, students' perception towards school and school life has been a important target in school improvement studies. The major factor that determines students' perception is school climate $[4,5]$. In recent years, many studies have been conducted on the relationship between student perceptions of school climate and psychological, social and academic variables. These studies found that a positive school environment affects various student outputs. It was found that cultural and climate features are related to the academic success of students $[6,7,8,9]$, school satisfaction [10], sense of belonging to the school community [11], perception of interpersonal and environmental safety [12] and student behaviors and depressive symptoms $[13,14,15]$. In addition, in recent years, assessments conducted on climate features and the effects of schools have emphasized that further research are required on student perceptions and non-academic outputs [16].

The important questions which point out the role of schools in values education are as follow: Are students' adherence to fundamental values such as tolerance, honesty, and peace correlated with the psychological environment at school? Are students' adherence to humanitarian values and perception of school climate differentiated according to demographic variables such as gender? Does the student perception of the school environment have an effect on positive behaviors for fundamental humanitarian values? Although many studies have been conducted on the effect of school climate on the individual outputs of students, the relationship between perceived school climate and students' adherence to values has not been much elaborated. However; as a place where students spend most of their time, school can be effective regarding its psychological environment and perceived support of teachers and peers on learning humanitarian values and the tendency to behave in accordance with these values. For this reason, this study investigates the effect of three major elements of school climate; namely, teacher support, success orientation and perceived positive peer interaction-safe learning environment on students' adherence to humanitarian values.

\subsection{The Role of School Culture and Climate in Values Education}

Until recently, many scholars discussed organizational climate with organizational culture. An organization's climate and culture reflect not only values and behavioral 
patterns of formal organization but also their interpretations with regard to natural organization. Organizational climate refers to a range of prevailing attributes perceived by shareholders and that affect their behaviors and personalizing the organization $[17,18]$. On the other hand, school climate comprises features of the school environment that distinguish a school from others and affect the behaviors of school members. In other words, it is a characteristic of the school that is experienced by school participants, affects their behaviors and is based on perceived common behaviors at school [19].

School climate represents the psychological environment of the school. School employees and students interact with each other within this environment. Studies found that behaviors of both teachers and students is influenced by the school environment [11]. Because, positive atmosphere of school increases students' sense of belonging to the school and protects them against emotional and behavioral problems [20]. School climate is an important issue that needs to be analyzed as it also has a mission to teach values in addition to increasing students' success. To profit from the positive effects of school climate can provide a significant tool to reach objectives that are generally ignored in curricula.

In addition to increasing the academic success of students, one of the most important ideals of all educational systems is to enable students to acquire appropriate behaviors. Especially in societies with value crises, the purpose of bringing up a "kind person" in schools moves ahead of academic success. Consequently, questions such as "What kind of an educational model should be developed for the acquisition of humanitarian and moral values?" and "Is it possible to provide a moral education in a traditional curriculum through courses and practices?" are frequently asked and studies are conducted for answers. According to [21], the importance attached to traditional and religion-oriented moral and values education, education policies and practices, decreases as secularism increases and social structures change. Instead, it is emphasized that a moral orientation based on shared values of multi-cultural democratic societies should be taken into account. The target of enabling the new generation to acquire shared humanitarian values such as honesty, peace, and friendship can be a good reference point.

During the process of enabling students to acquire positive behaviors, importance should be given to how to increase the role and contribution of the school. This is because school plays a central role within students' lives during adolescence. The school's social climate is a significant variable that determines how people should behave in society $[22,14]$. For this reason, schools can be explained by using the "community" metaphor [23,24]. Furthermore, the major reform required for secondary schools is to turn these institutions into communities that are more interested in students and supporting them [25]. Studies on school environment indicate that a positive school atmosphere has an effect on academic and non-academic outputs of children.

Theoreticians studying adolescent development suggest that relationships based on trust are important for successful development [26]. For this reason, relationships between teachers and students and teacher support are regarded as significant indicators of positive school climate by researchers studying school climate [27,7]. These studies found that adolescents' perception of school climate is shaped by teacher support, student-teacher and student-student relationships, and that these relationships affect students in academic, psychological and social terms. For example, the study conducted by Crosnoe et al. [28] found that warm relationships between teacher and students positively affect their academic success. Reddy, Rhodes and Mulhall [29] reported that students' self-esteem and depressive symptom levels are related to teacher support at school. Similarly, Jia et al. [30] reported that three major dimensions of school climate; namely, teacher support, student-student support and autonomy in class, are positively correlated with self-esteem and academic success and negatively correlated with depressive symptoms. The research conducted by Arıman [31] found that factors of school environment such as administrative structure, teacher-student relationship, and school safety, have a significant effect on students' tendency toward violence.

According to Ryan and Bohlin [32], schools can affect values, attitudes, habits and thus, the overall behaviors of new generations. The most important mission of schools in terms of enabling students to acquire appropriate behaviors is to help them to develop a mental framework so as to distinguish between good and bad. This is because, the bright future of a society can be ensured only through well-trained and character-wise people. However, people with these characteristics should be trained. For this reason, schools are responsible for ensuring that students develop the values and skills required to enable them to exhibit appropriate ethical decisions and behaviors. In this sense, values and character education refers to the improvement of students' knowledge, skills and abilities in order to help them make reasonable choices. In values education, the quality of the school atmosphere and relationships between school shareholders are more important than traditional teaching methods.

In values education, schools play a significant role. As a result, people spend most of their time at school until a certain age. Administrator-teacher-student relationships, the psychological atmosphere at school and the learning environment, all play a significant role in students' acquisition of appropriate behaviors. Having great importance in values education, hidden curriculum is designed by behaviors, approaches, beliefs, values of manager and teachers; quality, values of school atmosphere; and pattern of student interaction within school and cultural attitudes [33]. These elements of the hidden curriculum are directly or indirectly correlated with school climate. School offers a suitable environment for students' social learning. In this process, teacher support and positive school climate 
improves students' adherence to school and enables them to acquire appropriate behaviors. The research conducted by Vieno et al. [11] reported that there is a relationship between students' perception of school climate and the sense of community at school. In other words, when students have a positive perception of school climate, their adherence to school and the effect of school on students, increases. Moreover, studies conducted by Battistich and Hom [34] and Bateman [35] found that there is a relationship between students' adherence to school, sense of community and democratic values, and their adherence to norms. Therefore, students' adherence to fundamental values and norms may be correlated with their perception of school and adherence to school.

Studies on school climate report that various dimensions of school climate are correlated with students' psychosocial development and academic success. However, studies that investigate the effect of school climate on students' adoption of values and their adherence to these values are limited. With this in mind, this research is based on the hypothesis that "school climate has a significant effect on students' adherence to humanitarian values". In other words, students at schools with positive environment are expected to have more adherence to humanitarian values such as friendship, peace, tolerance, and responsibility. Moreover, it is believed that at schools where teachers support students and higher expectations are created, students will adapt themselves better to humanitarian values. Considering that relationships between students are closely related to school climate, it is assumed that a safe learning environment and positive peer interaction will facilitate the acquisition of behaviors that are compatible with humanitarian values.

\section{Methods}

\subsection{Participants}

The study group consisted of students receiving education at secondary schools within the Elazığ province. A multi-stage sampling method was used to determine the sampling of the study. According to Büyüköztürk et al. [36] multi-stage sampling is a method to extract unit from study population in two or more stages. Accordingly, in the first stage, all schools within the study population were included in the sampling in order to improve the representation power of the research findings. In the second stage, criterion sampling method [36] was applied and only final-year students were included in sampling. The reason for including only final year students was to obtain more reliable results in order to measure the perception of school climate. Final-year students are exposed to school climate and its effects more than others as they spend more time at the same schools. In the third stage, those among the final-year students to be included in sampling were determined randomly. Accordingly, fifty final-year students from each school were included in sampling randomly and the study was conducted on them. However, in order to increase the representation level of those in science high school (a type of secondary school in Turkey), all final-year students were included in sampling.

A total of 1100 scales were given to students and 1094 of them were returned. As these scales were applied in the school environment, the return rate was high $(99.45 \%)$. The minimum sampling number included in the research was determined to be 657 students for 0.01 deviation. The study was conducted on 1094 students and thus, results of this study are sufficient for generalization.

The research was conducted in 21 schools: one science, six Anatolian (a type of secondary schools in Turkey), seven general and seven occupational high schools. A total of 1094 students, 540 females and 554 males, participated in the research. In terms of school type, 384 Anatolian, 320 vocational, 305 general and 84 science high school students comprised the study population. While $484(44.2 \%)$ of participants took part in values education activities given under the leadership of the Elazı g Provincial Directorate of National Education, $610(55.7 \%)$ did not take part in these activities. Age range of participants was 17 to 19 .

\subsection{Procedure}

The one page scales were given to students and there was no time limitation. Because of The Humanitarian Values Scale was a self-rating scale, the support of guidance counselors was asked to increase reliability of the scale and to obtain more reliable data. Just before applying the scale, counselors encouraged students to give sincere answers. Scales were applied to participants in the classroom during the guidance and orientation course.

\subsection{Measures}

Two scales were used to collect data in this research. These scales were:

School Climate Student Scale (SCSS) : Developed by Çalık and Kurt [1] with five-point likert type and consisting of 22 items. The grading scale was as follows: "Never=1" and "Always $=5$." The scale has three factors: (1) supportive teacher behaviors (eight items), (2) success orientation (four items) and (3) safe learning environment and positive peer interaction (ten items). The scale's original reliability and validity results, factor load values of items differed between .45 and .85 and the explained total variance was found to be approximately $45 \%$. Internal consistency coefficients (Alpha) that were calculated in order to determine reliability levels of factor scores differed between .77 and .85 . According to analyses on data of current study, Cronbach's Alpha internal consistency coefficients of "Supportive teacher behaviors," "Success orientation," and "Safe learning environment and positive peer interaction" were found to be $0.854,0.712$ and 0.726 , respectively. Internal consistency coefficient (Alpha) of the whole scale was found to be 0.837 . According to these 
results, it was found that the scale has sufficient psychometric features to measure students' perception of school climate.

Humanitarian Values Scale (HVS): Developed by Dilmaç [2] to measure students' adherence to humanitarian values. This scale has six dimension and 42 items. These dimensions are responsibility, friendship, peace, respect, tolerance and honesty. Each dimension consists of seven items. Scale items were defined as by students' self-assessment regarding their behaviors. For example, "I undertake responsibility" in the responsibility dimension, "I can accept ideas of anyone" in the tolerance dimension, "I feel uncomfortable about wars in the world" in the peace dimension, "I tell people around me that it is important to respect others" in the respect dimension, "I tell the truth regardless of the possible consequences" in the honesty dimension and "I visit my friends only when I need them" in the friendship dimension (reverse coded).

According to the original reliability and validity results of the scale, factor load values of items in this six-factor dimension differed between .36 and .79. Total variance explained by items was found to be $34.48 \%$. Internal consistency coefficient (Alpha) of the whole scale was found to be 0.92 . According to analyses on data of current study, the scale's Cronbach's Alpha Internal Consistency Coefficient was found to be 0.87. Cronbach's Alpha Consistency Coefficient regarding responsibility, friendship, peace, respect, tolerance and honesty dimensions was 0.725 , $0.778,0.718,0.789,0.695$ and 0.708 , respectively. According to these results, it was found that the scale has sufficient psychometric features to measure students' adherence to humanitarian values.

HVS is a likert-type scale that can be applied individually or in groups. Items of the scale were defined as a Likert-Type grading scale (A: Never, B: Rarely, C: Sometimes, D: Frequently, E: Always), Increase/decrease in scores indicated that students adopt values more/less.

Participation to Values Education Activities (PVEA): Another variable is the attendance in activities related to values education. The notice no. 53 issued by the Ministry of National Education (Turkey) on September 13, 2010 stipulates to plan and implement activities in order to enable students to acquire the aforementioned values all across Turkey. In this scope, the Elazığ Provincial Directorate of National Education has been conducting activities to enable students to acquire national and humanitarian values in all schools in the province since the 2011-2012 academic year. Values to be acquired are defined in a certain theme concept and relevant activities are performed in line with this theme at school level. Some activities related to values education in the Elazığ province are as follow: Goodness Box, Generations Meet, Sister-Brother Matches, Towards Active Citizenship for Europe, Gift Balls Activity, I Have a Sibling There, I Share my Toy, Hope Stars, Safe Community, Safe Elazığ [37]. These activities are performed in all elementary and in some high schools. Therefore, it was considered that the participation of students in these activities would positively affect adherence to humanitarian values and Participation to Values Education Activities (PVEA) was included in the research as a variable. In this scope, we conducted interviews with school managers and gathered information about whether the participants in this study participated in these activities or not. The values of "1" and " 0 " were recorded in the data's statistical records for those who had participated and those who had not, respectively. DUMMY was included in regression model as a variable.

For data analysis, the obtained data were recorded in a special package program with a suitable numbering system for the survey format. The same program was used to analyze the data. Mean, standard deviation, correlation analysis and multiple regression analysis methods were used in data analysis.

\section{Results}

Table 1 presents the variables descriptive statistics and the comparison of females' and males' scores obtained from the scales.

According to the students' responses to the school climate scale, it can be said that supportive teacher behaviors $(\mathrm{M}=2.76)$, success orientation $(\mathrm{M}=3.39)$ and safe learning environment $(\mathrm{M}=3.34)$ are not satisfactory for students. Accordingly, students do not think that their school climate is sufficient in terms of teacher support, success orientation and safety of the learning environment. It is remarkable that especially teacher support is perceived at very low levels (Table 1).

It can also be said that the mean scores of adherence to humanitarian values are relatively high [responsibility $(M=3.57)$, friendship $(M=3.97)$, peace $(M=3.69)$, respect $(\mathrm{M}=3.76)$, tolerance $(\mathrm{M}=3.96)]$. On the other hand, interestingly, students stated that their adherence to "Honesty" is at lower level $(\mathrm{M}=3.28)$ than other values. It is thought-provoking that students adopt honesty, which is one of the fundamental values, at lower levels and exhibit behaviors of this dimensions less (Table 1).

Female and male students perceive learning environment and teacher support at different levels. Analyzing the mean scores of these dimensions, it was found that the difference was in favor of female students (Table 1). In other words, female students believe that they have a safe learning environment and that teachers exhibit supportive behaviors more than male students do.

A difference was found between female and male students in terms of adherence to humanitarian values. Analyzing the mean scores of dimensions, it was found that the difference was in favor of female students in all dimensions. Adherence of female students to humanitarian values such as responsibility, friendship, peace, respect, tolerance and honesty is more than the adherence of males.

The correlation matrix representing the relationship between variables is presented in Table 2 . 
Table 1. Descriptive statistics of variables and the results of t-test with regard to the gender variable

\begin{tabular}{|c|c|c|c|c|c|}
\hline \multirow{2}{*}{ Variables } & \multicolumn{2}{|c|}{ Male } & \multicolumn{2}{|c|}{ Female } & \multirow{2}{*}{$\mathbf{t}$} \\
\hline & Mean & Sd & Mean & Sd & \\
\hline Perception of School Climate & 3.09 & .60 & 3.18 & .63 & $-2.46^{*}$ \\
\hline Supportive teacher behaviors & 2.71 & .93 & 2.81 & .84 & $-1.95 *$ \\
\hline Success orientation & 3.38 & .91 & 3.40 & .85 & -0.49 \\
\hline $\begin{array}{l}\text { Safe learning environment and positive peer } \\
\text { interaction }\end{array}$ & 3.28 & .72 & 3.39 & .73 & $-2.49 *$ \\
\hline Humanitarian Values & 3.60 & .49 & 3.81 & .44 & $-7.48 *$ \\
\hline Responsibility & 3.49 & .66 & 3.65 & .62 & $-4.10 *$ \\
\hline Friendship & 3.84 & .76 & 4.10 & .70 & $-5.76^{*}$ \\
\hline Peace & 3.52 & .71 & 3.86 & .63 & $-8.45^{*}$ \\
\hline Respect & 3.69 & .75 & 3.83 & .68 & $-3.18^{*}$ \\
\hline Tolerance & 3.83 & .61 & 4.09 & .52 & $-7.38^{*}$ \\
\hline Honesty & 3.22 & .55 & 3.34 & .55 & $-3.68 *$ \\
\hline
\end{tabular}

$* \mathrm{p}<.01$

Table 2. Correlation Matrix on the Relationship between Variables

\begin{tabular}{|c|c|c|c|c|c|c|c|c|c|c|c|}
\hline & A & 1 & 2 & 3 & B & 4 & 5 & 6 & 7 & 8 & 9 \\
\hline A. Perception of School Climate & 1 & & & & & & & & & & \\
\hline 1. Supportive Teacher Behaviors & $.81^{* *}$ & 1 & & & & & & & & & \\
\hline 2.Success Orientation & $.73^{* *}$ & $.63^{* *}$ & 1 & & & & & & & & \\
\hline 3. Safe Learning Environment & $.73^{* *}$ & $.24^{* *}$ & $.28^{* *}$ & 1 & & & & & & & \\
\hline B. Humanitarian Values & $.40^{* *}$ & $.34^{* *}$ & $.37^{* *}$ & $.24^{* *}$ & 1 & & & & & & \\
\hline 4. Responsibility & $.33^{* *}$ & $.33^{* *}$ & $.31^{* *}$ & $.15^{* *}$ & $.75^{* *}$ & 1 & & & & & \\
\hline 5. Friendship & $.27^{* *}$ & $.20^{* *}$ & $.26^{* *}$ & $.19^{* *}$ & $.75^{* *}$ & $.50^{* *}$ & 1 & & & & \\
\hline 6. Peace & $.32^{* *}$ & $.29^{* *}$ & $.27^{* *}$ & $.18^{* *}$ & $.78^{* *}$ & $.48^{* *}$ & $.45^{* *}$ & 1 & & & \\
\hline 7. Respect & $.29^{* *}$ & $.30^{* *}$ & $.29^{* *}$ & $.12^{* *}$ & $.83^{* *}$ & $.62^{* *}$ & $.52^{* *}$ & $.63^{* *}$ & 1 & & \\
\hline 8. Tolerance & $.26^{* *}$ & $.18^{* *}$ & $.26^{* *}$ & $.18^{* *}$ & $.65^{* *}$ & $.39^{* *}$ & $.41^{* *}$ & $.41^{* *}$ & $.43^{* *}$ & 1 & \\
\hline 9. Honesty & $.28^{* *}$ & $.18^{* *}$ & $.20^{* *}$ & $.25^{* *}$ & $.55^{* *}$ & $.24^{* *}$ & $.32^{* *}$ & $.37^{* *}$ & $.33^{* *}$ & $.24^{* *}$ & 1 \\
\hline
\end{tabular}

$* * \mathrm{p}<.01$

Table 3. Results of Multiple Regression Analysis

\begin{tabular}{|c|c|c|c|c|c|c|c|}
\hline Independent Variables & $\mathbf{R}^{2}$ & $\Delta \mathbf{R}^{2}$ & B & SE & $\boldsymbol{\beta}$ & $\mathbf{t}$ & $\mathbf{p}$ \\
\hline Constant & & & 3.81 & .02 & & 188.44 & .00 \\
\hline 1st Step & .049 & .049 & & & & & \\
\hline Gender (Male) & & & -.21 & .028 & -.22 & -7.47 & .00 \\
\hline 2nd Step & .056 & .007 & & & & & \\
\hline PVEA (Participants) & & & .08 & .029 & .08 & 2.89 & .00 \\
\hline 3rd Step & .219 & .163 & & & & & \\
\hline Success orientation & & & .03 & .005 & .23 & 6.50 & .00 \\
\hline Teacher support & & & .01 & .002 & .16 & 4.63 & .00 \\
\hline $\begin{array}{l}\text { Safe learning environment and positive peer } \\
\text { interaction }\end{array}$ & & & .008 & .002 & .12 & 4.25 & .00 \\
\hline \multicolumn{8}{|c|}{$\begin{array}{l}\text { Dependent variable: Adherence to humanitarian values } \\
\qquad R^{2}=0,219 ; \mathrm{F}=60.873 ; \mathrm{p}=0.000\end{array}$} \\
\hline
\end{tabular}


According to Table 2; there are significant and positive relationships between all dimensions of school climate and humanitarian values scales $(\mathrm{p}<.01)$. There is a significant relationship between students' perception of school climate and adherence to humanitarian values $(\mathrm{r}=.40)$. In other words, the change in students' perception of school climate brings along the change in adherence to humanitarian values in the same direction.

The correlations between students' perception of school climate and responsibility, friendship, peace, respect, tolerance and honesty dimensions differ between $r=.26$ and $\mathrm{r}=.33$. The table shows that the highest level of relationship with school climate was found in the responsibility and peace dimensions. Students' perception of school climate is more correlated with their adherence to "responsibility" and "peace" values. Similarly, correlations between other dimensions are also significant (Table 2).

The correlation between students' perception of schools' success orientation and adherence to humanitarian values is higher than other dimensions. $(\mathrm{r}=.37)$. Taking stand from this finding, it can be said that a success-oriented school climate has a stronger relationship with students' adherence to humanitarian values.

According to these results, it was found that a positively perceived school climate has a statistically significant correlation with students' behaviors that are compatible with humanitarian values. It also can be said that positive school climate can highly contribute to the adoption of these values and behavior in accordance with these values.

Table 3 presents the results of multiple regression analysis conducted to determine the effects of school climate dimensions on students' adherence to humanitarian values.

According to Table 3, the gender variable included in the model at the first stage of regression analysis is a significant predictor of students' adherence level to school $\left(\Delta \mathrm{R}^{2}=.049\right.$; $\beta=-.22 ; \mathrm{t}=-7.47 ; \mathrm{p}<.01)$. The negativity of coefficient indicates that being male has a negative effect on adherence to humanitarian values.

The variable of "Participation to Values Education Activities" included in the analyses in the second step is a significant predictor of adherence to humanitarian values $\left(\Delta \mathrm{R}^{2}=.007 ; \beta=.08 ; \mathrm{t}=2.89 ; \mathrm{p}<.01\right)$. In other words, participation to activities related to values education given under the body of the Elaziğ Provincial Directorate of National Education significantly affected the scores obtained from the humanitarian values scale.

School climate dimensions included in the analysis in the third step are significant predictors of adherence to humanitarian values $\left(\Delta \mathrm{R}^{2}=.163 ; \mathrm{F}\right.$ change $\left.=75.47 ; \mathrm{p}<.01\right)$. According to the results of t-test on regression coefficients and the significance of these coefficients, it was found that success orientation $(\beta=.23 ; \mathrm{t}=6.50 ; \mathrm{p}<.01)$, teacher support $(\beta=.16 ; \quad \mathrm{t}=4.63 ; \quad \mathrm{p}<.01) \quad$ and safe learning environment-positive peer interaction dimensions $(\beta=.12$; $\mathrm{t}=4.25 ; \mathrm{p}<.01)$ significantly contributed to regression model. All variables in the model explain approximately $22 \%$ of students' adherence scores to humanitarian values. Approximately $16.3 \%$ are related to school climate (Table 3).

\section{Discussion and Conclusions}

According to the study findings, students think that teacher support, success orientation and safe learning environment are not at the desired level in their schools. Especially teacher support is perceived at lower levels. According to the scores obtained from the humanitarian values scale, students' adherence to responsibility, friendship, peace, respect and tolerance was found to be at high levels. However, interestingly, it was found that adherence to honesty was low.

The research illustrates that there were significant differences between females' and males' scores obtained from both school climate and humanitarian values scales. Females perceive teacher support and learning environment more positively than males do. Similarly, other relevant studies also determined that $[38,39,31]$. The gender variable has an effect on perception of school climate and female students perceive school climate more positively. In a study conducted by Dindar [40], it was found that female students are more interested in counseling activities and they can communicate with teachers and managers more comfortably. In parallel with these findings, Goodenow and Grady [41] found that males' sense of belonging to school is lower compared to females.

It was found that female students are more sensitive than males in terms of adherence to humanitarian values as well. In other words, female students have a higher level of adherence to humanitarian values. In parallel with the findings of the present study, a study conducted by Uyguç [42] on university students found that the importance attached to values by females and males differ, and female students pay more attention to values such as equality, charity, real friendship and responsibility. Similarly, Keskin [43] found that female students have a higher level of adherence to tolerance, solidarity, sensitivity to natural environment, charity, hospitality, fairness and responsibility values.

According to the study findings, it was found that there are statistically significant and positive relationships between all dimensions in school climate and humanitarian values scales. It was found that the relationships between general means and between perception of school climate and responsibility, and peace and respect dimensions of the humanitarian values scale, were stronger. Consistent with these findings, it was found that students' perception of school climate is positively correlated with the adherence level to humanitarian values. In other words, a school's positive climate positively affects students' adherence to humanitarian values.

Multiple Regression Analysis detected that the gender variable is a significant predictor of adherence to 
humanitarian values. Males' adherence to humanitarian values is lower compared to females. This finding confirms the results of the t-test. Moreover, the participation in values education activities positively predicts adherence to humanitarian values. As is expected, participation in values education programs organized at school level positively affects students' adherence to humanitarian values. However, regression coefficient indicates that this effect is not high. However, this finding is of importance as it shows that values education programs create a difference on students' adoption of values.

Another major finding of this research is that three important components of school climate, which are teacher support, success orientation and safe learning environment-positive peer interaction, are significant predictors of students' adherence to humanitarian values. In other words, students' perception of school climate significantly affects their adherence to humanitarian values. In a climate where the expectations from students are high, teachers support students and students feel safe; students' adherence to humanitarian values and their tendency towards acting in line with these values increase. Other studies in the literature also found similar results. For example, in a study conducted by Güçkıran [44], it was found that perceived school climate has an effect on students' tendency toward violence. Moreover, the research conducted by Vieno et al. [11] reported that there is a relationship between students' perception of school climate and the sense of community at school. In other words, when students have positive perception of school and teachers, the effect of school on students increases. Battistich et al. [45] and Bateman [35] found that there is a relationship between students' adherence to school, sense of community and social behaviors, democratic values, and adherence to norms. Therefore, students' adherence to fundamental values and norms are correlated with their perception of school and adherence to school. Similarly, Foa, Brugman and Mancini [13] found that there are strong relationships between the quality of school atmosphere and students' orientations to social norms and their behaviors. Behaviors and adherence to humanitarian values of people who consider themselves as a part of a school community are positively affected. This result shows us that teachers, administrators and other staff at schools should endeavor to create a more positive school climate so as to enable students to internalize humanitarian values and turn them into behaviors.

According to Haydon [46], teachers are not only responsible for students' moral development but for creating a reliable ethical environment. Such an environment can be created through quality school culture and climate in addition to teacher efforts. For this reason, it is important to create a suitable school environment for teaching values. Leming [47] believes that the effect of direct teaching methods on character development is low (as stated in the present study). However, it is reported that character development occurs in the most efficient way in social networks and environment with a motivating and supportive atmosphere. The study results and other studies support the idea that school climate is a significant predictor of students' behaviors.

As stated in the educational administration literature, high success expectation from students and a success oriented school climate are fundamental features of effective schools $[34,48]$. Moreover, effective schools do not only improve students' academic success but also create a suitable environment to enable students to acquire appropriate behaviors. Therefore, the relationship between positive climate features and students' suitable behaviors to humanitarian values, which was revealed in this study, supports this idea. Effective schools create success-oriented, supportive and safe learning environments and enable students to acquire humanitarian values. The relevant studies report that trust-based and supportive relationships are important for successful social and emotional development especially in adolescence [26,30,49]. For this reason, the quality of school environment is very important during the adolescent. Furthermore, administrators and teachers should exhibit supportive behaviors and create a school climate where students can feel safe and develop positive relationships with their peers.

\section{Limitations and Future Research}

Although this study contributes to our understanding on relationship between perceived school climate and adherence to humanitarian values in adolescents, it is limited in certain respects. First, adherence and commitment to humanitarian values may be affected by many individual and environmental factors such as family and neighborhood characteristics, socio-economic status, race. But, these factors were not included to current study. Therefore, future studies examining different variables might serve to further understanding the associations between individual-environmental factors and adherence to human values. Second, three aspects of school climate (teacher support, success orientation and safe learning environment-positive peer interaction) were included to this study. But, other features of school climate such as school connectedness, order and discipline, school psysical environment [10] might have influence on students' adherence to social values and norms. Therefore, further studies might examine effects of other aspects of school climate. Third, There are limited studies on effectiveness of values education activities. Current study were included attendance to these activities as a control variable. But, further study examining affects of interactions between school climate features and value education activities on students' commitment to values and norms might serve to our understanding the associations between school characteristics, values education activities and students' adherence to values. 


\section{REFERENCES}

[1] Çalık, T. ve Kurt, T. (2010). Development of school climate scale. Education and Science, 35(157), 167-176.

[2] Dilmaç,B. (2007). An examination of the humane values education program on a group of science high school students. Unpublished Doctoral Dissertation. Selçuk University, Institute of Social Sciences, Konya, Turkey.

[3] Bandura, A. (2001). Social cognitive theory: An agentic perspective. Annual Review of Psychology, 52, 1-26.

[4] Fan, W., Williams, C.M. \& Corkin, D.M. (2011). A multilevel analysis of student perceptions of school climate: The effect of social and academic risk factors. Psychology in the schools, 48(6), 632-647.

[5] Zullig, K., Koopman, T., Patton, J. \& Ubbes, V. (2010). School climate: Historical review, instrument development and school assessment. Journal of psychoeducational assessment, 28(2), 139-152.

[6] Good, T.L. \& Weinstein, R.S. (1986). Schools make a difference: Evidence, critisizm, and new directions. American Psychologist. 41(10), 1090-1097.

[7] Roeser, R., Eccles, J., \& Sameroff, A. J. (1998). Academic and emotional functioning in early adolescence: Longitudinal relations, patterns, and prediction by experience in middle school. Development and Psychopathology, 10(2), 321-352.

[8] Steward, E.B. (2007). Individual and school structural effects on African American high school students' academic achievement. The High School Journal, 91(2), 16-34.

[9] Demirtaş, Z. (2010). The relationship between school culture and student achievement. Education and Science, 35(158), $3-13$.

[10] Zullig, K., Huebner, E.S. \& Patton, J.M. (2011). Relationships among school climate domains and school satisfaction. Psychology in the schools, 48(2), 133-145.

[11] Vieno, A., Perkins, D.D., Smith, T.M. \& Santinello, M. (2005). Democratic school climate and sense of community in school: A multilevel analysis. American Journal of Community Psychology, 36, 327-341.

[12] Derosier, M.E. \& Newcity, C. (2005). Students' perceptions of the school climate: Implications for school safety. Journal of School Violence, 4(3), 3-19.

[13] Foa, C., Brugman, D. \& Mancini, T. (2012). School moral atmosphere and normative orientation to explain aggressive and transgressive behaviours at secondary school. Journal of Moral Education, 41(1). 1-22.

[14] Kasen, S., Johnson, J. and Cohen, P. (1990). The impact of school emotional climate on student psychopathology. Journal of Abnormal Child Psychology, 18(2), 165-177.

[15] Loukas, A. \& Robinson, S. (2004). Examining the moderating role of perceived school climate in early adolescent adjustment. Journal of research on adolescence, 14(2), 209-233.
[16] Huebner, E.S., Gilman, R., Reschly, A., \& Hall, R. (2009). Positive schools. In S. J. Lopez \& C.Snyder (Ed.), Handbook of Positive Psychology (2nd Ed.). New York: Oxford University Press.

[17] Çelik, V. (2002). School Culture and Management. Pegem Academy Publishing, Ankara.

[18] Ertekin, Y. (1978). Organizational climate. TODAİE Journal, 44(12). 16-35.

[19] Hoy, W.K. \& Miskel, C. (2004). Educational Administration: Theory, Research, and Practice. New York: McGraw Hill.

[20] Hawkins, J.D. \& Catalano, R.F. (1990). Broadening the vision of education: schools as health promoting environments. Journal of School Health, 60(4), 178-181.

[21] Sarid, A. (2012). Between thick and thin: responding to the crisis of moral education. Journal of Moral Education, 41(2), 245-260.

[22] Cartland, J., Ruch-Ross, H.S. \& Henry, D.B. (2003). Feeling at home in one's school: A first look at new measure. Adolescence, 38, 305-319.

[23] Kohlberg, L. (1985). The just community approach to moral education in theory and practice. In M.W. Berkowitz \& F. Oser (Eds.), Moral Education: Theory and Application (pp.219-238). Hillsdale, Nj: Lawrence Erlbaum.

[24] Sergiovanni, T. (1994). Building community in schools. San Fransisco: Jossey-Bass Publisher.

[25] Hargreaves, A., Ear, L., \& Ryan, J. (1996). Schooling for change: Reinventing education for early adolescents. Bristol, PA: Falmer, Taylor \& Francis.

[26] Roeser, R., Eccles, J., \& Sameroff, A. (2000). School as a context of early adolescents' academic and social-emotional development: A summary of research findings. The Elementary School Journal, 100(5), 443-471.

[27] Pianta, R. C., Nimetz, S. L., \& Bennett, E. (1997). Mother-child relationships, teacher-child relationships, and school outcomes in preschool and kindergarten. Early Childhood Research Quarterly, 12(3), 263-280.

[28] Crosnoe, R., Johnson, M. K., \& Elder, G. H. (2004). Intergenerational bonding in school: The behavioral and contextual correlates of student-teacher relationships. Sociology of Education, 77(1), 60-81.

[29] Reddy, R., Rhodes, J. E., \& Mulhall, P. (2003). The influence of teacher support on student adjustment in the middle school years: A latent growth curve study. Development and Psychopathology, 15(1), 119-138.

[30] Jia, Y., Ling, G., Chen, X., Ke, X., Way, N., Yoshikawa, H., Hughes, D. \& Lu, Z. (2009). The influence of student perceptions of school climate on socioemotional and academic adjustment: A comparison of Chineese and American adolescents. Child Development, 85(5), 1514-1530.

[31] Arıman, F. (2007). Researching the relationship between the school climate and the bullying tendancy among the 7 th and 8th grade students in primary schools. Unpublished Master Thesis, Yeditepe University, Institute of Social Sciences, İstanbul. 
[32] Ryan, K., S Bohlin, K. E. (1999). Building character in schools. San Francisco: Josey-Bass Publishers.

[33] Tezcan, M. (2003). Hidden curriculum: A conceptual analysis in term of educational sociology. Turkish Educational Sciences, 1(1), 53-59.

[34] Battistich, V., \& Hom, A. (1997). The relationship between students' sense of their school as a community and their involvement in problem behaviors. American Journal of Public Health, 87(12), 1997-2001.

[35] Bateman, H. V. (1998). Psychological sense of community in the classroom: Relationships to student's social and academic skills and social behavior. Unpublished doctoral dissertation, Vanderbilt University, Nashville, TN.

[36] Büyüköztürk, Ş., Çakmak, E.K., Akgün, Ö.E., Karadeniz, Ş. ve Demirel, F. (2010). Scientific Research Methods. Pegem Academy Publishing, Ankara.

[37] Arabacı, İ.B. ve Akgül, T. (2011). Best practices in values education. Values Education Symposium, 26-28 October 2011, Osmangazi University, Eskişehir, Turkey.

[38] Özdemir, S., Sezgin, F., Şirin, H., Karip, E. ve Erkan, S. (2010). Examining the variables predicting primary school students' perceptions of school climate. Hacettepe University Journal of Education, 38, 213-224.

[39] Kuperminc, G.P., Leadbeater, B.J., Emmons, C. \& Blatt, S.J. (1997). Perceived school climate and difficulties in the social adjustment of middle school students. Applied Developmental Science, 1(2), 76-88.

[40] Dindar, M.M. (2008). Comparing the perception of school climate of the students who take education in different kinds of secondary schools. Unpublished Master Thesis, Yeditepe
University, Institute of Social Sciences, İstanbul.

[41] Goodenow, C. ve Grady, K.E. (1993). The relationship of school belonging and friends' values to academic motivation among urban adolescent students. Journal of Experimental Education, 62(1), 60-71.

[42] Uyguç, N. (2003). Gender, personel values and choice of profession. Dokuz Eylül University Faculty of Economics and Administrative Science Journal, 18(1), 93-103.

[43] Keskin, Y. (2008). Values education in social sudies teaching curriculums at Turkey: Historical development, researching of 1998 and 2004 curriculums effectiveness. Unpublished Doctoral Dissertation, Marmara University, Institute of Educational Sciences, İstanbul.

[44] Güçkıran, R.Y. (2008). The relationship between school climate perceptions and aggression levels of primary school students. Unpublished Master Thesis, Yeditepe University, Institute of Social Sciences, İstanbul.

[45] Battistich, V., Solomon, D., Watson, M. \& Schaps, E. (1997). Caring school communities. Educational Psychologist, 32(3), 137-151.

[46] Haydon, G. (2004). Values education: sustaining the ethical environment. Journal of Moral Education, 33(2), 115-129.

[47] Leming, J.S. (1981). Curricular activities in moral/values education: A review of research. Journal of Moral Education, 10(3), 147-164.

[48] Balc1, A. (2001). Effective School and School Improvement (Second Edition). Pegem A Publishing, Ankara.

[49] McEvoy, A. \& Welker, R. (2000). Antisocial Behavior, Academic Failure, and School Climate. Journal of Emotional and Behavioral Disorders, 8(3), 130-140. 